\title{
Intercultural household food tensions: a relational dialectics analysis
}

\begin{abstract}
Purpose: Recent global migration trends have led to an increased prevalence, and new patterning, of intercultural family configurations. This paper is about intercultural couples and how they manage tensions associated with change as they settle in their new cultural context. The focus is specifically the role food plays in navigating these tensions, and the effects on the couples' relational cultures.
\end{abstract}

Design/methodology/approach: A qualitative relational-dialectic approach is taken for studying Polish-Irish intercultural couples. Engagement with relevant communities provided multiple points of access to informants.

Findings: Intercultural tensions arise as the couples jointly transition, and food consumption represents implicit tensions in the household's relational culture. Such tensions are sometimes resolved, but sometimes not, leading to enduring tensions. Dialectical movement causes change, which has developmental consequences for the couples' relational cultures.

Research limitations/implications: This study shows how the ways that tensions are addressed are fundamental to the formation of a relational family identity.

Originality/value: Dealing simultaneously and separately with a variety of dialectical oppositions around food, intercultural couples weave together elements from each other's cultures and simultaneously facilitate both relational and social change. Within the relationship, a stability-change dialectic is experienced and negotiated, while at the relationship's nexus with the couple's social ecology, negotiating a 
conventionality-uniqueness dialectic enables them reproduce or depart from societal conventions, and thus facilitate social change.

\section{Key words}

Relational dialectics; Intercultural families; Food consumption

\section{Introduction}

Significant shifts in global migration over recent decades have led to the increased formation of intercultural families, forged through the blending of cultures, and resulting in new family formations facing challenges as they settle in their cultural context (Lindridge et al., 2016; Castles and Miller, 2009). Around 3.3\% of the world's population is settled outside their country of birth, and in many western countries the figure is $14 \%$ and rising (United Nations 2017). Several studies have indicated that immigration, globalization and acculturation are important macrofactors influencing the likelihood of meeting, interacting with and marrying someone from another culture (Berry, 1997; McFadden and Moore, 2001; Qian and Lichter, 2007). Thus, it has become increasingly appropriate to speak of transnational or intercultural couples and families. There have been several calls for researchers to account for the dynamic changes in culture that result from the increasingly frequent and complex interactions between the people, products and practices from several cultures (Luedicke, 2015, 2011; Yaprak, 2008). Yet, as a cultural and social phenomenon, intercultural families represent an under-researched family or household form (Bystydzienski, 2011; Cross and Gilly, 2013).

Within consumer research, there has been a shift towards viewing the family as a relational unit. Epp and Price (2008) advocate a greater emphasis on how bundles 
of relational identities moderate the socialization of central family practices. This perspective has underpinned recent studies of sibling relations (Kerrane et al., 2015), intergenerational consumption (Karanika et al., 2016), senior families (Huff et al., 2016), long-distance families (Epp et al., 2014), and immigrant households (Lindridge et al., 2016). Molina et al. (2004) highlight the tensions, conflicts and challenges for intercultural relationships as they work towards creating a family relational culture, that is, the private set of meanings, symbols, rituals and values that provide consensual order within the family unit (Wood, 1982; Farrell et al., 2014). While relational culture is dynamic and adjusts through the changing pressures and contexts of the family unit (Conville, 2008), for the intercultural family unit, the relational work involved in forging a relational culture can be expected to be particularly challenging given the initial differences, not least in terms of consumption habits and the oppositional or contradictory aspects captured therein (Kalmijn, 1998).

This paper focuses on the role of food in the development of relational culture within intercultural couples (Conville, 2008). Our research asks how intercultural tensions are manifested and reconciled, and how family relational culture develops in the creation of family practices around food (Silva et al., 2012). We view such tensions through a relational dialectic lens, a rich framework focusing on the management of oppositions whilst locating the negotiation of family relationships within broader, extant external sets of relationships.

We first provide an overview of the theoretic framework of relational dialectics, within which we consider the intercultural family, followed by the context and methods for this study. We then present our findings relating to the key dialectical 
tensions associated with food consumption. Finally, we discuss our findings, considering the implications for theory and public policy in this domain.

\section{Literature review}

\subsection{Relational dialectics}

Building on Bakhtin's work on dialogism (1981; 1984), relational dialectic theory is used to explore the tensions between unity and difference in all aspects of social life. Bakhtin argues for the simultaneous presence of opposing forces within each utterance and therefore more broadly across social life. Centripetal forces drive towards unity and operate to establish a common, standardised ground of communication and action, while centrifugal forces emphasise difference, stratification and the plurality of perspectives on the ideal or correct way of living (Baxter, 2004). The notion of simultaneous conflicting forces towards unity and distinctiveness forms the basis of relational dialectic theory, which has been used extensively to examine various aspects of family relational dynamics (e.g. Baxter et al., 1999; Sabourin, 2003), and more recently in a study of family consumption dynamics (Davies and Fitchett, 2015). The core insight arising from the application of relational dialectic theory to family lies in seeing the family as a site where different, opposing and unified voices come together, regarding the tension between unity and difference as a key aspect of the formation of family units, rather than an abrasion or flaw. Dialectical opposites are interdependent with one another and in this way opposites are accommodated to enable adequately unified position in a relational system. From our theoretic perspective we treat tensions as a fundamental feature of relationships (Baxter and Montgomery, 1996), and regard the interplay of competing 
and unifying positions and voices as an energizing source of vitality that shapes the continuously emergent relationship (Baxter, 2004).

Many theorists view relational change as omnipresent and on-going (Baxter and Montgomery 1996; Brown et al., 1998; Bochner et al., 1996). The dialectic position has also been used to show relationship development as a relatively stable trajectory, yet one that is punctuated by periods of instability (Conville 2008). Some envision relational change as a spiral (e.g. Baxter and Montgomery, 1998; Conville, 2008), arguing that relational transitions transform the relationship into its next developmental phase. To explain how change occurs in a relationship, Conville (2008) distinguishes two dialectical pairs that reflect the stages of a relationship (security-alienation and disintegration-resynthesis) as meta-dialectics. For Conville (2008), this change process involves relationship partners responding to one dialectical opposite (e.g. need for intimacy and closeness), which in turn creates pressure to attend to the opposite (e.g. need for space and time alone). Over time, the relationship couple or pair cycle back and forth between responsiveness to the opposing demands, but importantly they never return to the same place as before. The dialectical movement results in relational transformation and development, moving the relationship through stages of interdependence, certainty and closeness (Brown et al., 1998; Conville, 2008). Taking this perspective, consumer stories are not representational accounts of their relationships, but, as Bochner et al. (1996) argue, an instrument of being, shaping how participants become who they are. The metadialectics transforms the relationship through multiple developmental phases (Conville, 2008).

Relational dialectics analysis therefore builds from the notion of simultaneous centrifugal and centripetal forces to provide a theory of family communication. This 
perspective recognizes that family life is "a both/and experience - families gain their meanings from the give-and-take interplay of multiple, competing themes and perspectives" (Baxter, 2006 p.131). Families exhibit simultaneous fusion with, yet differentiation from, members; participants fuse their perspectives to some extent while sustaining the uniqueness and difference.

\subsection{Relational dialectics, culture and the intercultural family}

All couples face tensions in their relationships; dialectic theorists classify these tensions as internal (within the relationship) and external (with those outside the relationship). When couples seek to negotiate these tensions, they are "doing relationship work" (Conville, 2008), and resolution of tensions requires dialectical movement (or change), which has developmental consequences for the couple's relational culture (Kemmer et al., 1998). In the context of intercultural families, the picture is complicated further since each partner draws on their own experiences and personal family relational culture, set within and influenced by their national relational culture. Cross and Gilly (2014) studied binational couples and found that individual partners relinquish part of their personal cultural identities to gain a synergistic collective family identity. In a subsequent study, Cross and Gilly (2017) found that family composition, shared conceptualization and context lead to blending processes as families seek to accommodate different cultural backgrounds. Crucially, Cross and Gilly $(2014,2017)$ view this adaption process as balance or equilibrium driven, suggesting that compensatory mechanisms are introduced to "even out the perception of "sacrifice" (2014, p 122). However, a relational dialectic theory does not conceptualise relating to others as being equilibrium driven (Baxter, 2004). Relational dialectic theorists view balance as distinctly non-dialogic, simply a holding action in which two phenomena, or oppositions, coexist but do not interpenetrate 
(Baxter, 2004). Dialogue is a centripetal-centrifugal flux and in dialogue, voices interpenetrate one another and thereby constitute and change one another.

When an intercultural couple seeks to resolve consumption-related tensions, probing "the interplay of reciprocal bundles of identities within the family" (Epp and Price, 2008 p.60) helps reformulate the way we think about such tension or conflict resolution. Davies and Fitchett (2015) showed that a dialectic approach helped overcome the problems of cultural transmission down family chains, acknowledging how mother-daughter relations were not fixed identity positions, but rather continually emergent within the context of these relationships. Within an intercultural couple the dialectic approach helps reveal how the partners seek similarity through difference but also difference through similarity. Identity positions are not fixed, rather they are interwoven as the interplay of competing identities is negotiated and managed.

Given the complexity of the interaction of culture with family relational culture, it is important to recognise that tensions and contradictions surrounding change are located in a variety of social units - the individual, the relationship, the family, the social group and the culture (Brown et al., 1998). The relational dialectic approach provides a way to examine intercultural couples managing their relational culture in the context of tensions, contradictions and change.

\subsection{Relational dialectics and the intercultural family}

Understanding acculturation and enculturation is important for revealing how cultural elements are incorporated into the relational culture, this providing insights into the couple's enculturation. Acculturation describes how a person copes or 
manages the tensions inherent in settling in a new socio-cultural context (Berry, 1997). Enculturation involves incorporating cultural elements during socialization (Weinrich, 2009); in a consumption context, enculturation describes the non-deliberate learning that occurs within a relationship. A premise of dialectic analysis is that tension related to a component of family life deemed central to the family or intercultural identity (e.g. food consumption) must be resolved satisfactorily for smooth family relations. Such tensions require a 'both/and' approach, leading to a fusing of perspectives, while sustaining and embedding uniqueness in the relational identity. A synthesized solution around food, for example, may serve particular identity needs such as expressing the relational identity of the family. In their study of second generation South Asian women living in Britain, Lindridge et al., (2004, p231) found that food consumption was one source of conflict between the immigrants' in-home and out-of-home consumption. While within home consumption was not a source of tension, consumption outside the home was more complex, since it often required conforming to the wider British culture.

Cross and Gilly (2013) also show a similar movement as couples use compromising strategies around food consumption. Cross and Gilly (2013, p454) describe the "mixing up - the compromise - is a matter of a little of his and a little of hers", acknowledging the importance of maintaining a cultural equilibrium in the relationship. Any unresolved tensions can prevent re-synthesis and, by implication, relational transition (Basseches, 1984). Conville's particular approach (using metadialectics) helps illuminate the interdependence among the dialectical opposites, and therefore the interdependent learning (enculturation) that is a feature of the relationships. This contrasts with Cross and Gilly (2014, p.135) who focus on intercultural learning as being "through the cultural understanding of the native 
spouse", thereby suggesting that the non-native partner's cultural competence is not an interdependent feature of the couples' enculturation.

To summarise, in this research we aim to explore how intercultural tensions around food, how these are negotiated within intercultural families, and what this process reveals about such families' relational cultures.

\section{Context and Methods}

The study context is Ireland, a distinctive regional space of migration and mobility, with recent data revealing that almost $12 \%$ of the population was born outside Ireland (compared to $6 \%$ in 2002). The largest group of 'East-West (European) free movers' (Favell, 2008) in the immigration boom since 2004 originates from Poland. In this research, we focus on Polish-Irish families, providing a two-sided empirical account of the relational culture of intercultural families.

Our study aimed to include intercultural couples that had established a household together for at least two years. We adopted a purposive approach to participant recruitment, using personal contacts of the lead researcher to identify Polish-Irish couples. This approach yielded eight couples, who subsequently introduced us to the remaining seven couples ( 2 couples are related). The 15 couples (Table 3.1) fully participated in the individual and joint interviews (an additional 7 couples were identified, but for various reasons did not participate). Recognising the need to reflect the broad spectrum of social relationships characterising contemporary families (Harrison and Gentry 2007), we aimed to recruit couples that varied in terms of their marital status, sexuality and religion.

INSERT TABLE 3.1 HERE 
We adopted a flexible approach to our research to reflect multivocality (Baxter, 2006, p.140), using a combination of methods (see Table 3.2).

\section{INSERT TABLE 3.2 HERE}

The aim of the Stage 1 interviews was to give voice to people's lives and worldviews (Belk et al., 2013). Stage 2 joint interviews allowed us to explore the jointly constructed meanings based on the emerging themes from Stage 1. Our approach acknowledges that families communicate at relational levels, so their conflicts around consumption may be especially revealing (Yerby, Buerkel-Rothfuss and Bochner, 1998).

Family researchers have debated the issues and merits of interviewing family members together or apart (Wong et al., 2016; Hertz, 1995). We chose both, to facilitate private and individual consideration of acculturation experiences, and then a deeper joint reflection on the changes in consumption over the course of their relationship. All interviews were conducted over a one-year period (2015/2016). The individual interview used open-ended discussion points (Hill and Somin, 1996) to enable the participants to convey meaning in their own terms (Belk et al., 1989; McCracken, 1988, Thompson et al., 1989). Initial "grand tour" questions (McCracken, 1988) encouraged talk about food consumption, including discussion of changes (or not) after setting up home together. Open-ended questions followed, to develop insights into the intercultural relationship, how this related to food consumption practices, and the differences and tensions over food. Individual interviews took place in participants' homes, workplaces or other mutually agreed locations, lasting between 60-90 minutes. Interviews were recorded, transcribed and coded, and from this, discussion themes for the joint interview emerged. Joint interviews were also conducted in locations chosen by participant, with discussion focused on the tensions 
around food consumption revealed in the individual interviews. Analysis of the joint interview narratives focused aspects of food consumption important to them, often prefaced with the word "we". The joint interview allowed for the production of a jointly constructed narrative (with partner interacting, negotiating, contradicting or supporting each other) (Newholm and Hopkinson, 2009), yielding insights into the couples' unique relational cultures.

Consistent with an interpretive approach, all interviews were analysed using comparative analysis (Fischer and Otnes, 2006). As the data gathering progressed we constantly compared informants and emerging themes. This iterative process tacked back and forth between the data and the literature (Glaser and Strauss, 1967; Bradford and Sherry, 2014; Cross and Gilly, 2014). Full ethical approval was established. Participants were given an information sheet, and were asked for informed consent and permission to have the interviews recorded. All participants were given pseudonyms, as were any family/friends mentioned. While it is not unusual for interviews with couples to accidentally expose tensions in the relationship between household members thereby creating discord (Gill, 1999), we sought to minimise such tensions by emphasising before each interaction that the discussion was limited to food consumption.

\section{Results}

Our analysis identifies a range of relational dialectic tensions around food, illustrating the strategies used to address these tensions as they relate to wider relational development. Analysis is framed around key tensions related to food practices that our intercultural families face. 


\subsection{Tensions around defining 'good food'}

For Polish and Irish partners coming together to form combined relational cultures, defining what constituted 'good food' represented a key point of tension. Notably, participants were able to describe their understanding of the other culture's food, and often prefaced food descriptions with the terms "Irish" or "Polish". In some cases, this demarcation is quite specific (e.g. Polish/Irish milk), while in other cases particular brands or particular foods or dishes are demarcated as Polish or Irish (e.g. Polish participants describing 'fish and chips' and 'Chinese takeaway food' as typically 'Irish'). In addition, for the immigrant partners, differences in eating practices are often portrayed as representing a tangible loss of culture, providing an illustration of an internal tension negotiated within the dyad:

Natia: ...that is the difference... food is different... and I would find it very hard if I had to rely only on Irish food ...I feel like here in Ireland I am losing my tradition; that is why I want to keep my traditions...

Matthew: I could live on Polish food no problem...like Irish food is extremely bland in comparison... every Polish kitchen has a drawer full of flavourings and it makes the food absolutely beautiful, that is what I find brilliant about Polish food.

For Polish participants, food tensions reinforced feelings of unfamiliarity in new surroundings, emphasising the cultural distance they faced. Natia describes how she feels she is losing her culture, and is committed to keeping her traditions intact. Irish food culture was perceived as lacking the elaboration and involvement of Polish food, and was generally viewed as being unhealthy and overly reliant on convenience. These sentiments were echoed across other participants who spoke of food in terms of 
cultural difference, exemplified by Aldona describing her changing food habits since arriving in Ireland. This narrative highlights the 'knot of contradictions', with the internal (within the dyad) intersecting with the external (relations with extended family):

Aldona:... we grew everything at home, everything organic... when I came here, I could not believe... it was only a matter of opening 2 packets... pasta and another packet for a sauce... So, that for me was like step back ... but I was trying to more mix in Irish (foods)... so, I would be chancing things to try different foods... and then I would be trying to cook them... but sure that's how I learned... Yeah it was hard at the start...

James: You see after we got married, there were no Polish shops here... but now there are five and I just took to the Polish foods straight away, so when there's anything on here, like when my family come to visit... some of them even go in and shop in the Polish food shop and get the sausage that they liked... and that opened their eyes to it... when they used to come for parties here, it was all Polish food...

Aldona: Introducing it... like I say, I respect your traditions, you have to respect mine... I love it (the Polish shop), it's not that I'm shopping there every (day)... I go if I need it... if I have a taste for sausages I just go and buy it, I know I have the option...

James: But I was kind of in on the traditions of your culture before that...

Dialectical tensions arise when partners are drawn to one pole of the opposition and then the other; such tensions introduce dynamism to the relationship (Conville, 2008). Through their food choices, James and Aldona manage the competing demands of 
their two identities. The food served on visits by extended family and friends is nonconventional (in relation to Irish foods), and this departure marks the couple's identity as unique, thereby facilitating social change. James has lost something of his birth culture but has also gained an intercultural relationship, which helps redefine him. Aldona, through immigration, has gained an intercultural relationship where her foods can be re-located and shared. The couple is not in some idealized state of balance; rather they have fulfilled competing needs simultaneously, though this is only a temporary moment in their on-going adaptation to dialectical flux (Montgomery, 1993). James and Aldona do not demonstrate dualistic thinking, or compromise, rather they demonstrate change - the food served is non-conventional, and this departure marks out the couple's identity as unique, thereby facilitating social change. As Baxter (2004 p187) puts it, “the parties' selves are given shape through relating”, representing a form of "co-construction of selves" (p187). In negotiating this loss and gain dialectic, we see an example of the dialectic strategy of integration. Inherent in this interplay is reciprocal learning, demonstrated at the nexus of the couple's relational culture with extended family.

While the Polish participants emphasized difference and strangeness in their accounts of Irish food culture, many Irish partners focused on similar features, using these to assert the essential similarity of cultures. Several Irish partners spoke of Polish foodstuffs as somehow resurrecting an authentic Ireland that had been lost from the plate, a form of an external tension, shown here in Tony's comments:

Tony: It's very traditional... their hams, their cheeses... their meats... much cheaper... and far tastier... just because it is... proper food... it is all processed on the Irish market... 
Their introduction to Polish food is positioned as a rediscovery or reintroduction, of what Tony describes as "proper" food. Tony appears to partially support the dominant Polish view around the lack of distinctive Irish food culture, but also poses a contradiction in terms of praising the processed products of Poland (ham, cheese), which lies in opposition to the processed character of Irish food. Here is a perception that processed foods represent traditional and authentic foods, but only if the products have come from the Polish shop. In this framing of tradition, we get a sense of invented tradition, "a process of formalization and ritualization, characterized by reference to the past, if only by imposing repetition" (Hobsbawm, 1983, p.4). This acts as a device that re-casts the essential differences that the Poles found so startling, thus providing a backdrop for acculturation and enculturation. While processed foods are viewed as a point of tension for both cultures, fundamentally, both cultures are equating processed foods with something quite different. For the Polish participants, the Irish reliance on processed foods equals cheap, unhealthy, and convenience, whereas for the Irish participants, processed in Polish food culture is linked to tradition and authenticity, and therefore more readily embraced and revered by the Irish participants. The Polish partners expressed strong and largely derogatory views about Irish food along with the perceived superiority of their food traditions and fear of the loss of their culture. Nevertheless, the particularities of everyday eating and the role and use of elements from both cultures demonstrate the unity of opposites, and reveal the relational dialectic as the couples negotiate a process of contradictory discourses.

There were other stories of food tensions emergent in the early stages of relationships: 
Kasia: At the beginning I was struggling to find a bread that I would like ... remember the soda bread that I was always buying when you met me? I always had it at home...

Kevin: McCambridge's...

Kasia: Yes, so that was one brand that for me...has some meaning, one Irish brand that if I wanted to buy a...good healthy bread, I would kind of buy that one... it kind of has good memories as well, because we used to eat that together...

This is a very personal and individualized take on the tension around finding 'good' and 'healthy' bread, resolved by Kasia finding a bread that worked for her. 'Bread' came to symbolize aspects of their shared culture when they first met. Throughout our study, in similar accounts of how both partners have been confronted by unfamiliar notions of what it is 'right' to eat and when, both have adapted, demonstrating simultaneous processes of acculturation and enculturation.

In other instances greater autonomy is maintained. Patrick and Magda approached bread consumption differently and, since Patrick did not like Polish bread, the two "don't compromise it", instead making individual and separate food choices around bread.

Patrick: You know...I don't like their bread...that's one thing...kind of a minor disagreement. I just don't like it... so we will go our separate ways... she will eat the Irish bread, but she prefers the Polish, so she will get that in the Polish shop, there wouldn't be arguments over it or anything, we just don't compromise it... 
Going on to talk about their food practices more generally:

Patrick: We go to Poland and we come back with great intentions and then we...

Magda: Yeah...in the first year (together) we put more effort into it...but then our son was born...

Patrick: We used to go shopping together but now that doesn't really work that well...

Magda: No it doesn't... one of us stays to look after (son)... but I would think about Patrick (in the Polish shop)... I would always think...

Patrick: It's funny I think the way we split brands... I mean... there's certain things where it doesn't bother us and we would probably buy in Aldi ${ }^{1}$, but there's certain things where it does bother us and you will stick to Dunnes ${ }^{2}$.

In the interplay of oppositions described in the narratives we get an insight into the dynamic interplay of opposing forces (Montgomery, 1993). The partners seek to fulfil the competing tendencies (satisfying individual tastes vs. connection with partner) that are a feature of their relationship. Patrick is clear about what foods he does not like, and through their shopping and food consumption, Patrick and Magda manage these contradictory demands simultaneously. A dualistic balance is not achieved (on some choices the couple remain on opposite poles of the contradiction), and there is not a permanent resolution of the various dialectic tensions. Indeed, relationship maintenance is practiced as the partners adapt and change. Canary and Stafford (1994) defined relationship maintenance as the communications practices by which

\footnotetext{
${ }^{1}$ German international discount retailer, primarily sells food, clothes and household wares

${ }^{2}$ Irish multinational retail chain, primarily sells food, clothes and household wares
} 
partners sustain and restore the satisfaction and commitment levels of their partnership. These practices are not just verbalised, they involve actions such as assisting with tasks. Miller (1998 p.3-4) observed that shopping practices often signify that the choices made "are a sign that you have shown some care", which is a feature of Magda's choices here. Patrick's observation about their brand choices is also instructive, and further indicates that as they seek to manage contradictory demands around convenience, tastes and preferences, there is interplay of opposing forces.

\subsection{Tensions around food within the changing family unit}

As couples established their new lives together, they adjust eating patterns towards the creation of 'blended' food practices, combining aspects of Irish and Polish food. For some, differences in cultural aspects of food and eating were a source of tension early in the relationship, linked to expectations of the type and quantity of food eaten, as well as role expectations in regard to division of household labour around food.

Amalja: In the beginning I tried a lot, I would make soup, not like a starter in a restaurant but soup...that was your dinner and he was "What's next"... I was shocked... you just had it! And then he gets up and goes and makes sandwiches...it was embarrassing because in Poland women always cook for men... but now, if I don't feel like cooking I don't and he is fine with that... he cooks... that has changed in my life now. 
Oliver: We eat fairly Irish food really...earlier on in the relationship we would have eaten more Polish stuff Amalja would cook; she doesn't seem to do it now as much... now we are... basic meat and two veg.

Amalja describes the different assumptions she and her Irish partner, Oliver, hold in relation to what constitutes a meal, while also raising different expectations in relation to food provision roles. A source of tension in the early days, these tensions are now resolved and habituated for her. Though her partner notices the shift from 'tension' to 'resolution', he downplays this, apparently not recognising the extent of the issue for Amalja. However, Oliver also pointed out that he missed particular Polish dishes:

Oliver: There is one dish... it's a chicken, a whole chicken and they bone it and stuff it with mince and sage and onion and it is just ...ah it's fantastic ...I'm dying for her to cook it...the little dumplings as well, pierogi, they're very nice.

While this household's food consumption has evolved and is not strongly influenced by Polish ingredients, Oliver's comments suggest a movement towards the opposing pole of the dialectic. Putnam (1999, p 148) noted that there can be cultural pressures to subsume differences through "joint life projects", and in the case of intercultural couples, there may be moments when one partner relinquishes their own preferences in deference to their partner's tastes (as with Amalja). In the following excerpt, David and Jozephina talk about how food consumption changed, but also how it led to relational change around trust.

David: At the beginning there was a problem with food alright...

Jozephina: Yeah... it was garlic (Laughs)... I like garlic and I like it everywhere... 
David: Everything tasted the same... and I said...you don't allow the food's own taste to emerge... Irish dinner... like the potatoes, the bacon and the cabbage... and that all has its own flavour... but Polish have to mix it up, oh you have to have some onions, some garlic... herbs... and I found this was a big problem at the start... so I cooked some foods and said eat it just the way it is... there were new tastes, like I brought you haddock and you never had haddock before...

Jozephina: Yeah I loved it... now I don't use as much herbs...

David: It took a long time for Jozephina to trust my opinion I think... she used to argue with me about everything... (Laughs) I don't know, I suppose she didn't know me long enough...

Jozephina: Well (laughs)... he thinks that I... you know, don't trust him... you see, I had to get used to it in some kind of way...

David: Yes, I like to try different things... I used to go to the Polish shop before I met you... just because I was curious... We're both quite open too like... to experience new things... so it works very well.

Through this couple's narrative, an example of an internal tension within the relationship, we see a movement from stability to disintegration. Jozephina prioritised foods familiar to her, reflecting her own personal taste and culture, but not taking account of David's taste. This represented a source of tension for the couple ("I found this a big problem from the start"), and they reached a critical turning point ("eat it just the way it is"), reflecting the dialectic attributes of contradiction, dynamism (towards change) and interdependence ("It took a long time for Jozephina to trust my opinion”). Re-synthesis occurred because both are open to change (an openness- 
closedness dialectic) and a new stability, characterised by greater interdependence in food preparation and consumption is the outcome. There is mutual responsiveness and adaptation as both partners' food preferences are reaffirmed.

Rachela and George provide an account of the change to eating habits related to the presence of children.

George: When Rachela would be alone with the kids, she would cook something (Polish)... like the Polish chicken soup... but she would compromise and do what I eat, when we are together...

Rachela: Yeah, most of the time they (children) are eating only Polish soups...they don't like the Irish soups... the canned soups or the cartons or anything like that...

George: On the odd occasion... maybe... I would like the meat, the ham... and then the sausages... But I still prefer my Irish bread!

Rachela: I am only giving the girls... most of the time, the Polish bread. They are only having the toast... toast with butter in the evening from the Irish bread... other than that it is only Polish bread...

George: And in regards to the prices on things, if Rachela enjoys the Polish food, whatever price it is we'd get it because we won't compromise on the price.

Rachela will cook mainly Polish foods for her children when she is alone with them, representing an attempt to ensure that aspects of the Polish relational culture are continued through the children's eating practices. While George states explicitly that Rachela compromises in her eating habits when they are together, from Rachela's 
perspective, she only talks about the children's preferences for the Polish food (no mention of her own), stating that they actively do not like the Irish food. Their slightly differing versions of family eating practices hints at an acceptance of their situation, although the comments about toast in the evening or eating Polish ham, suggest there is movement towards each other's food cultures. Dialectic tensions over food are interrelated and resolved in several ways, as shown by comments from George about not compromising on the price of Polish product, and how shopping occurs at both mainstream supermarkets and the Polish shop. These tensions are a form of Brown et al.'s (1998) knot of dialectic contradictions, as the couple's bread consumption oscillates back and forth from Polish to Irish (the toast and butter). From a dialectical perspective, the opposing forces in a relationship will always be fluctuating to some extent, as the partners experience change (Baxter and Montgomery, 1996).

Not all our intercultural couples managed to reconcile their differences. Early experiences with food in the intercultural context were often tension inducing. While in some cases new foods were embraced, in other cases food is still a source of residual tension, as Tereska explained:

Tereska: At the start, I was trying to cook a bit of Polish stuff, but Keith didn't like it... So ... almost every day...it's Irish dinner not Polish... but like it can be chicken curry ... not really Irish but ...you know what I mean? That's what Keith likes... so I am trying to cook more what he likes.

This residual tension over food has not been resolved and is also demonstrated in Keith's narrative:

Keith: She cooks a lot more Polish food than she says she does; I think she might not even notice it... there's a few nice Polish dishes that I would like... 
but I like getting take-away and stuff like that... pizza ... that's an Irish thing for her... and then the... foods she might only eat because of me... Chinese food ...so it's more or less...Irish...she probably only eats that because of me...

Tereska's compromise over household food consumption reveals what dialectic theorists refer to as spiralling inversion, of unresolved dialectic tensions; Keith acknowledges the tension but does not compromise on his food preferences. For Tereska, the compromise leads to unresolved tension and her occasional consumption of food items from the Polish grocery, which she describes as "for my pleasure" indicates a strategy of separation. As the exemplars above highlight, relational culture is highly dynamic and dialectical (Conville, 2008); each couple creates their relational culture and amends it. In their everyday food consumption, unique rituals, idiosyncratic language and symbols have also come to characterise the couples' relational identity (Farrell et al., 2014). In the following section, we examine how relational culture is transacted around special occasions.

\subsection{Tensions around food for special occasions}

Belk et al. (1989) argue that the creation and expression of the sacred, and the maintenance of its distinctiveness from the secular, is prominent in consumption practices. In forwarding this argument Belk et al. (p.31) highlight culture and family, stating, "sacredness exists at a cultural level to ensure the on-going integrity of the culture itself'. The primary locus of the sacred is the dwelling - sacred because it houses the family. Given the role of culture and family in both maintaining and marking the special we anticipate meaningful differences across these as contexts and in the tensions surrounding the development of intercultural families. Across the 
sample, Christmas was an important festival that highlighted a series of relational tensions ostensibly related to food consumption. Within the consumption space of Christmas, discussion centred on the development of shared socialization processes and rituals, that combine to produce communitas (Turner, 1972) and family social order for their intercultural unit. The processes of meaning investment and divestment for Christmas food socialization rituals was the entrée for the discussion with Amalja and Oliver:

Amalja: Poland has a big Christmas Eve... Ireland have a big Christmas day... it took my husband about 6 years to come to first Christmas Eve, because ... 'I don't understand anything, I don't like the food'... and then there is blessing the food and going on your knees and all that... so the usual we say, go and get a few drinks in the pub... he never came back! That's how it was...until I threaten him and I say listen... it is your choice but ... when the kids came I said I want them to know where I come from, we already have where you come from, we live in it ... if you're not going to come Christmas Eve, I'm not going to do Christmas day... since then, he goes for the kids, more than me...for the tradition, but he does go...

Oliver: We always go to Aldona's (sister-in-law) house and it's good actually because... on Christmas Eve, I would go to the pub, and fall home then when you were kicked out kind of... but... we go and there is no drink involved and it is all sort of traditional meals and there's little things like soup with pierogi (dumplings) and there's a coin in one of them... and this is the tradition... the kids are all very involved ...

For this family, the central tension is around developing a shared commitment to a sacred time and space in relation to Christmas celebrations. Sacred is partly defined in 
terms of opposition to the profane or ordinary/everyday, and thus it is important that the new shared understanding of, and approach to, celebrating Christmas protects and maintains its sacred status by ensuring it is positioned clearly in opposition to the everyday. Christmas Eve is a particular flashpoint, a tension for the intercultural family. For the Irish partner, Christmas Eve is a time for drinking and relaxing, in anticipation of the main focal celebrations of Christmas Day, which contrasts with the Polish framing of Christmas Eve as the central event. Part of Oliver embracing the Polish rituals around Christmas involves a divestment of his own Irish cultural practices to develop the new family ritual, important for their children's wider sociocultural understanding of food. Oliver also embraces the foods associated with the Polish Christmas Eve meal, recognizing the totemic aspects of the sacred here, notably the special food linked to the mythology and mystery of Christmas. Bruess and Pearson $(1997,2002)$ suggest that partners in a romantic relationship may be more likely to disclose to each other during rituals that are unique to their relationship and that play a role in defining their relational culture. Oliver and Amalja's negotiation of the Christmas ritual is not just ritualistic and symbolic; it also reveals how a relational identity is co-produced through meaningful interactions within their relational culture (Pearson et al., 2011).

From a relational dialectics perspective, Conville (2008) illustrates how partners in a relationship move from security to disintegration, when a tension causes one or other partner to notice their relationship, "instead of simply being in it" (Conville, 1991 p.93). Uncertainty is created and alienation may occur if one of both parties question the relationship as presently constituted. There is a desire to restore security, so the partners seek a solution that Conville (2008) refers to as a resynthesis. From the narratives around the Christmas Eve celebration, Amalja and Oliver move 
from security (as a couple in their everyday consumption) to disintegration (over the way they will celebrate Christmas). This leads to tensions and possibly feelings of alienation. At this alienation stage they come to a turning point, where they reach the dialectic opposite of security, and something has to be done to regain security. Christmas Eve is ostensibly the focus, but its implications for the relationship are enacted obliquely. The change in the relationship happens automatically as they resolve their tensions around celebrating Christmas. The re-synthesis indicates a transformation in the relationship, and occurs because the Christmas celebration has been reframed and represents a new interdependence, with an emphasis on the importance of the children. When they talked about Christmas and its meaning (during the joint interview) they emphasized how they have evolved a set of food practices and routines around the celebration of Christmas, a sacralization of the rituals that have come to capture the quintessence of the sacred aspects of Christmas for this intercultural unit. The sacralization of rituals around the celebration of Christmas demonstrates mutual responsiveness and adaptation, as well as the interpenetration of cultural backgrounds and food consumption in their relational culture. Their narratives reveal tensions at the interface of the relational and the cultural, how these are dealt with and how a new security phase is entered.

Understanding the symbolic nature of rituals within relational cultures is crucial because their presence appears to be necessary for healthy interpersonal relationships (Campbell and Ponzetti, 2007). Rook (1985) noted that rituals are enacted within communities, are used to reflect social norms and can be used to dramatize status transition. On some occasions, participants reported consuming foods that were not to their taste, but which they felt they ought to consume, particularly if ritual was involved. McCorkindale (1992) noted that the sensory evaluation of food, 
not only measures variable responses to the taste stimulus, but is also made within the parameter of social acceptability. A traditional dish served on Christmas Eve is carp, often problematic for the Irish partners. For example, Patrick reported "I struggled with the carp, for good manners to be honest with you...", while Rachela reported her accommodation of her husband George's distaste for this dish: "George won't eat the carp, too many bones... so I will do the chicken... in five different ways...". Chicken replaces fish, which is also notable, as the traditional Polish Christmas eve dinner involves twelve courses, with no meat served. Rachela instead replaces the fish dishes with chicken, and observes:

Rachela: And we invite George's parents and other friends and... they eat everything, all the traditional dishes I have prepared and ... the Polish tradition would to greet people with greetings... and you would go around the table... and break the bread...

So even though it is an occasion that is regulated by cultural and social norms, preferences are accommodated within the relational culture. If, as Douglas (1972) observed, meals are representative of social relationships between the participants, we see that in the relational culture of the intercultural couple. George and Rachela use the symbolic consumption to highlight flexibility, observed in other studies of immigrant populations (Cwiertha and Walraven, 2002). This tension - feeling the need to conform to tradition or how things are done while acknowledging individual tastes and preferences - features regularly, but is often rationalized. Rituals are relational enactments (Baxter 1987) as they help manage inherent dialectic tensions and represent a type of cultural expression. Rituals also play a central role in creating, revising, reinforcing and passing on family identity (Epp and Price, 2008). 
Easter is another special occasion where food practices are brought to the fore. The families attempt to co-construct an Easter celebration, involving elements both religious and/or secular, with emphasis placed on the inclusion of family, friends and sometimes the wider community. As Sandikci and Ger (2010) note, migrants and locals may become co-producers of meanings and practices. For the families we see them trying to find unifying features that can be shared but also to locate differences, illustrating the simultaneous unity and difference that is a feature of dialectic understanding. For the Polish partner, the familiar tastes of Easter dishes are a reminder of home:

Magda: Like our borsch...the kind of the white soup with eggs and eh...probably some kind of roast meat...the Polish type...and I would paint the eggs...every year!

and when talking about Easter, childhood memories are often invoked:

Magda: Remember last year when we were in Poland, all different types... eggs... and... and you can blow them out you know and then you paint them... decorate the shell which is like a cool thing to do...

Easter celebration has been constructed using largely Polish elements, and is framed as a unique expression of the couple's identity. The apparent privileging of Polish Easter rituals and many Polish symbols appear to happen partly because there are so few Irish elements available to choose from. Hugh explains how he tries to find suitable Irish elements to include:

Hugh: Like for instance at Easter, despite all the dishes they make, they would want me to participate as well, so ... actually I would always do the leg of 
lamb... albeit it wouldn't be... but they enjoy it ... so you know you get to pick... and pick some of the good things out of both cultures.

Some of the ritual is constructed around religious elements, for example Dorata explains what is new about the celebration for her husband Peter:

Dorata: On Saturday we are painting the eggs and we have the... you know holy basket, so that is a new one and I love these traditions...

Peter elaborates:

Peter: And a lot of my family do it, but they do it with us, so like we paint the eggs and bring them up to the church and get them blessed.

As these examples indicate, consumption ritual constructed around Christmas and Easter also enable the couples to build relationships with extended family, even with somewhat different approaches in practice. The Irish partner was much more likely to use particular food brands or services, for example introducing extended family members to the Polish grocery, while the Polish partner was more likely to use inclusion in traditional or modified Polish ritual. John, for example, was acutely conscious that his father-in-law, who had expressed initial doubts about the marriage, was also very close to Cela, so when they went to visit him at Easter:

John: He loves Paddy whiskey and we have a collection of Irish whiskeys over there that I have started...I brought a bottle or two with me at Easter...

The Easter ritual enables maintenance of Polish tradition and an inclusion of extended family members, but also a recreation of an Irish celebration or tradition that is perceived as lost. 


\section{Discussion}

Our analysis explored a range of intercultural tensions, and how the family relational culture develops in the creation of family practices around food (Silva et al., 2012). The use of relational dialectics theory in this study facilitates a close examination of intercultural dialectic tensions, ostensibly relating to food, but indicative of some tension in the relational culture, which is negotiated and managed within the intercultural household. This research is important since recent understandings of the family in consumer research have shifted towards considering families as comprising a unique relational culture, wherein consumption takes place (Lindridge et al., 2016; Cross and Gilly, 2014). Within the intercultural context, understanding of the unique relational culture is complicated by the broader cultural context, emphasizing the importance of acculturation and enculturation theory (Peñaloza 1989; Davies and Fitchett, 2010) in this setting.

Our research uncovered some key points of tension for the intercultural family in relation to food practices, mainly in terms of constructions and understanding of 'good' food; the wider social dimension of acceptable foods for sharing and how the changes to the family unit impacted on food practices; and tensions around sacred food practices. Through this focus on intercultural couples resolving these food tensions, we uncovered a number of important new insights around development of family relational culture.

The first contribution relates to the resolutions of tensions, and the way that balance or compromise is approached. Cross and Gilly (2014) describe how intercultural couples engage in a cultural learning process that seeks to "even out" or address the cultural imbalance experienced by the immigrant partner in the new 
setting. While we witnessed that broadly the reconciliation of tension was through flexibility in approach to food, we also saw instances where autonomy of cultural preference prevailed, and there was no compromise strategy for selecting everyday foods. We identified instances of unresolved dialectic tensions, acknowledged by both partners, and privately resolved through separation strategies (e.g. Tereska buying occasional food items from the Polish store). We show how intercultural couples must cope simultaneously with a variety of dialectical oppositions; balance or equilibrium is a fleeting moment within the temporal ebb and flow of the couples' on-going adaptation to dialectical flux (Montgomery, 1993). In the case of food, the couples can be interdependent with one another, while sustaining autonomy. Food can be used to enable the partners achieve both stability and novelty within their relational culture as well as at the nexus of their relational culture with others at the boundary of the relationship. Dialectic theorists (Braithwaite and Baxter, 1995; Montgomery, 1993) have noted that relationships are maintained to the extent that the partners can successfully manage, over time, the dynamic interplay of opposing tendencies. Couples never resolve contradictions into some idealised state; at a given moment competing needs may be fulfilled simultaneously and a couple may feel that they have transcended the contradiction. In a dialectic conception, such equilibrium is not a permanent resolution, rather a simultaneous transitory fulfilment of both poles of a contradiction. Braithwaite and Baxter (1995) note that relationship partners have a variety of ways of responding to dialectic demands, they may oscillate back and forth through time between efforts to fulfil first one pole of the contradiction, then the other. Our research shows participants achieving a form of balance in food consumption through a kind of 'holding action', whereby compromise is transitory and the two oppositions co-exist but do not interpenetrate. 
Second, exploring the negotiation of the tensions around food deepens our understanding of how intercultural families attempt to build tradition into their relational culture. Tensions and challenges are often shared and the couples attempt mediation, demonstrating a distinct intercultural practice of agency. This bidirectional intercultural process is in contrast with previous studies on consumer acculturation and adaptation, which have broadly conceptualised the relationship between the migrant and socialisation agents as being one-directional (Luedicke, 2011, 2015). Dialectically, this means that only the migrants' tensions with the culture of settlement are revealed. In our study we reveal more intimate intercultural tensions and therefore respond to Luedicke's (2015) call for greater insights into intercultural tensions. Cross and Gilly (2014), for example, suggest that the immigrant partner gains cultural competence through the non-immigrant partner; our study suggests that cultural learning or enculturation within intercultural households is a reciprocal and interdependent process. Food consumption also provides an important example of how intercultural family identity is co-constructed in action (Epp and Price, 2008). The participant couples in our study create a distinct intercultural agency, which they attempt to use as a resource not only to negotiate with others in their social milieu, but also as a representation of their relational culture. The descriptions and analysis of the tensions around food for visitors reveals the complexity of the interaction between internal/external tensions. The foods chosen in this context emerge from negotiations between the couple in relation to which foods are acceptable to them, but also what is considered good and special among their growing and wider social ecology. The tensions around food represent a "double reveal", in the sense that they show us what is going on within the relationship, but also show how the couple (using food) negotiate the tensions with the actors in their broader ecology. Within the intercultural 
couple's social ecology there are external tensions and we show how the couple negotiate the tensions with the actors in their broader ecology (e.g. extended family, friends, neighbors) alongside their focus on resolving internal tensions (linked to their couple dyad) (Conville, 2008). Returning to James and Aldona serving food at a social gathering, the tension for James is that he views himself as very immersed in Polish culture, and his family (Irish) see him as very different from them. Food represents one way of resolving this tension, a way of expressing his difference from them (the Irish) and showing his unity with Aldona. He is learning and enculturating this new identity, this expression of who 'we' are, where the food reflects something of them as a couple. If convention is challenged (for example, for the Irish family members going to a party and being served Polish foods instead of the expected Irish foods), then this introduces tension, which is a catalyst for some kind of social change as the relationship is revealed/comes into contact with friends and the wider social network. We therefore show how a relational culture changes and modifies within the dyad, we show its social impact and something of how the relational culture changes in the wider ecology.

A third contribution relates to how the intercultural couple constructs acceptable foods for the various social settings comprising their relational culture. As Askegaard and Kjeldgaard (2002) observed, people reflexively interpret the meanings embedded in consumption and marketplace resources differently, and this was the case in our study. Peñaloza (1989) demonstrated how consumer acculturation was an eclectic process of learning and that the ability to appropriate and master certain types of cultural knowledge was an antecedent of consumer acculturation. However, as Davies and Fitchett (2010) point out, this premise can be extended to consumer enculturation, recognizing that immigrant consumption practices may constitute an 
important type of cultural learning. Food consumption is a means of accessing intercultural knowledge and understanding, and may support individuals coping with cultural fracture (Davies and Fitchett, 2010). Our study shows how in the intercultural family setting, cultural fracture is jointly experienced; food consumption becomes a means for both cultures to engage in reciprocal or interdependent learning. Food rituals and consumption practices are exchanged with others in the families' social milieu indicating an attempted role as builders of cultural understanding and mediators of cultural exchange (Smith-Maguire and Matthews, 2014). The particularities of everyday eating and the role and use of elements from both cultures demonstrate keener awareness of difference than similarity, which underpins much of the tension faced. Our findings reinforce the importance of including children and other social actors in the wider social-cultural framing of food, especially through sacred events.

Based on our findings, it is apparent that the intercultural couple face a number of challenges, and our recommendations emphasise the importance of understanding how the family relational culture develops in the creation of family food practices. Askegaard (2006) observed that brands increasingly structure the way we see things; brands can mediate new types of sociality and new types of collective identity (Cayla and Eckhardt, 2008; Kipnis et al., 2014). Marketing can play an important role in changing culture (Thompson and Arsel, 2004) and therefore participate in the social construction of markets. Given the importance for the intercultural couple of retaining and incorporating tradition into their new food practices, marketers must look to ways of supporting the intercultural couple retain tradition, while smoothly navigating their new cultural context. The use of multiplecultural cues may appeal to consumers who have an intercultural identity, and enable 
marketers to use diverse cultural referents that communicate meanings congruent with this identity. Multiculturalism is a relatively new phenomenon in Ireland, the context of this study, and marketers have tended to adopt fairly homogenous approaches in their portrayal of Irish consumer culture. Our research aims to encourage marketers to look beyond such homogenous perspectives. As Turner and Rojek (2001, p.7) frame it, sociology seeks "to understand how social bonds are formed and sustained, despite rather than because of economic exchange." Revealing how intercultural households view food, how they come to be reflective of relational cultures, should encourage marketers to look beyond the purely economic and consider how one dimension of Irish social change - an increase in intercultural households, can uncover new insights into consumer behaviour.

The public policy implications of this study for society are several. Fostering a greater understanding of intercultural relationships enhances societal well-being; societal norms, for example on the role that "economic migrants" play in society are challenged. Rather than view people from an economic perspective, the impact of intercultural families in their wider social milieu enable intercultural understanding through enculturation. The intercultural couples have demonstrated the characteristics of the cultural intermediary in that they construct value by mediating how goods (or services, practices, people) are perceived and engaged with by others (Smith-Maguire and Matthews, 2014). In this broader social ecology, foods and food rituals become resources to be used as diplomatic gifts, as representational expressions or as an introduction to new cultural experiences. In considering the relational adaptation that has taken place within intercultural relationships, our work provides insights into the ways in which established social relations can change. The intercultural relational culture developed by the participants challenges essentialist notions of culture and 
shows how differences can be negotiated and accommodated. Social policy analysts may reflect on the ways in which the couples developed an intercultural identity rooted in each other's culture, how they draw on a range of strategies to demonstrate they can synthesize and successfully negotiate the challenges they face.

Regarding the limitations of our work, we covered one geographic location, and further work could explore other geographical settings to consider how intercultural relational identities are forged around food. The couples come from different cultural backgrounds, but are predominantly Roman Catholic European countries, both with a history of emigration and being colonized. While we endeavoured to include a range of family forms in this study (Ekström, 2003; Palan and Wilkes, 1997), this could have been widened further, and we recommend further widening of family demographics in subsequent work (e.g. including more same-sex couples; more Polish male/Irish female). Equally, research that looks beyond Polish/Irish dyads may reveal other equally interesting insights on the creation of their relational cultures and identities, as might inclusion of comparator intra-cultural couples (Cross and Gilly, 2013). Intergenerational interactions have been identified by several researchers as playing a crucial role in identity and well-being (Epp and Price, 2008; Lindridge and Hogg, 2006), and future research might extend to look at the wider family unit, bringing in immediate and extended family members to deepen understanding of the wider intercultural relational family.

\section{REFERENCES}

Askegaard, S. (2006), "Brands as a Global Ideoscape", in Schroeder, J. and M. Salzer-Moerling (Eds.), Brand Culture, Routledge, London, pp.91-102. 
Askegaard, S. and Kjeldgaard, D. (2002), "The Water Fish Swim In?: Relations between Marketing and Culture in the age of Globalisation", in Kuudsen, T., Askegaard, S. and Jorgenson, N. (Eds.), Perspectives on Marketing Relationships, Karnov Group, Copenhagen, pp.13-35.

Bakhtin, M.M. (1981), The Dialogic Imagination, University of Texas Press, Austin. Bakhtin, M.M. (1984), “Toward a reworking of the Dostoevsky book”, in Emerson, C. (Ed.), Problems of Dostoevsky's poetics, University of Minnesota Press, Minneapolis, pp. 283-302.

Basseches, M. (1984), Dialectical Thinking and adult development, Ablex, Norwood. Baxter, L.A. and Montgomery, B.M. (1996), Relating: Dialogues and Dialectics, The Guilford Press, New York.

Baxter, L.A and Montgomery, B.M. (2008), "A guide to dialectic approaches to studying personal relationships," in Montgomery, B.M, and L.A. Baxter (Eds.), Dialectic approaches to studying personal relationships, Psychology Press, New York.

Baxter, L. A., Braithwaite, D.O. and Nicholson, J.H. (1999), "Turning points in the development of blended families,"Journal of Personal and Social Relationships, Vol.16, pp. 291-313.

Baxter, L.A. (2006), "Relational Dialectics Theory: Multivocal dialogues in family communication", in Braithwaite, D.O. and L.A. Baxter (Eds.) Engaging Theories in Interpersonal Communication, Sage, Thousand Oaks.

Baxter, L. A. (1987), "Symbols of relationship identity in relationship cultures", Journal of Social and Personal Relationships, Vol.4 Issue: 3, pp. 261-280.

Baxter, L.A. (2004), “A Tale of Two Voices: Relational Dialectics Theory”, The Journal of Family Communication, Vol. 4 Issue: 3 \& 4, pp.181-192. 
Belk, R.W., Fischer, E. and Kozinets, R. (2013), Qualitative Consumer Marketing Research, Sage, London.

Belk, R.W., Wallendorf, M. and Sherry, J.F. Jr. (1989), "The Sacred and the Profane in Consumer Behavior: Theodicy on the Odyssey", Journal of Consumer Research, Vol. 16 Issue: 1, pp. 1-38.

Berry, J.W. (1997), "Immigration, acculturation and adaptation," Applied Psychology: An International Review, Vol.41, pp. 5-68.

Bochner, A.P., Ellis, C. and Tillmann-Healy, L.M. (1996), "Relationships as Stories”, in Duck, S.W. (Ed.), Handbook of Personal Relationships, Wiley, Chichester, UK, pp. 307-324,

Bradford, T.W. and Sherry, J.F., (2014), "Hyperfiliation and cultural citizenship: African American consumer acculturation”, Journal of Business Research, Vol.67 Issue: 4 , pp.418-424.

Braithwaite, D. and Baxter L.A. (1995), “The Relational Dialectics of Renewing Marriage Vows", Journal of Social and Personal Relationships, Vol. 12 Issue: 2, pp. 177-198.

Brown, B.B., Werner, C.M. and Altman, I. (1998), "Choice points for dialecticians: A dialectical-transactional perspective on close relationships", in Montgomery, B.M. and L.A. Baxter (Eds.), Dialectical Approaches to Studying Personal Relationships, Lawrence Erlbaum Associates, New Jersey, pp. 137-154.

Brownlie, D., Brewer, P. and Horne, S. (2005), "Culinary tourism: An exploratory reading of contemporary representations of cooking", Consumption, Markets and Culture, Vol. 8 Issue: 1, pp 7-26. 
Bruess, C.J. S and Pearson, J.C. (2002), "The Function of Mundane Ritualising in Adult Friendship and Marriage”, Communication Research Reports, Vol. 19, pp. 314-326.

Bruess, C.J.S. and Pearson, J.C. (1997), "Interpersonal Rituals in Marriage and Adult Friendships", Communication Monographs, Vol. 64 Issue: 1, pp. 25-46.

Bystydzienski, J.M. (2011), Intercultural Couples: Crossing Boundaries, Negotiating Differences, New York University Press, New York.

Campbell, K. and Ponzetti, J.J. (2007), "The moderating effects of rituals on commitment in premarital involvement", Sexual and Relationship Therapy, Vol. 22 Issue: 4, pp. 415-428.

Canary, D., and Stafford, L. (Eds.) (1994), Communication and Relationship Maintenance, Academic Press, New York.

Castles, S., and Miller, M. (2009), The age of migration: International population movements in the modern world, $4^{\text {th }}$ edition, Palgrave Macmillan, Basingstoke.

Cayla, J. and Eckhardt, G.M. (2007), “Asian Brands without Borders: Regional Opportunities and Challenges", International Marketing Review, Vol. 24, Issue: 4 pp. 444-456.

Chytkova, Z. and Kjeldgaard, D. (2011), "The modern woman myth as a means of cosmopolitan cultural capital accumulation: A gendered accumulation perspective", in Belk, R.W., K. Grayson, A.M. Muniz and H.J. Schau (Eds.), Research in Consumer Behaviour, Vol. 13, pp. 199-216.

Conville, R.L. (2008), “Telling Stories: Dialectics of Relational Transition”, in Montgomery, B.M, and L.A. Baxter (Eds.), Dialectic approaches to studying personal relationships, Psychology Press, New York. 
Cross, S.N.N and Gilly, M.C. (2013), "Consumption compromises: Negotiation and unification within contemporary families", Journal of Business Research, Vol. 67 Issue: 4), pp. 449-456.

Cross, S.N.N and Gilly, M.C. (2014), "Cultural Competence and Cultural Compensatory mechanisms in Binational Households", Journal of Marketing, Vol. 78 Issue: May, pp.121-139.

Cross, S.N.N and Gilly, M.C. (2017), "The impact of diversity on institutional longevity”, International Journal of Research in Marketing, Vol. 34, pp. 231-251.

Cwiertha, K. and Walraven, B. (2002), Asian Food: The Global and the Local, Curzon Press, Surrey.

Davies, A., and Fitchett, J.A. (2010), "Material man is not an island: Coping with Cultural Fracture", Journal of Marketing Management, Vol. 26 Issue: 11-12, pp.1005-1020.

Davies, A. and Fitchett, J.A. (2015), "In the family way: bringing a mother-daughter (matrilineal) perspective to retail innovation and consumer culture", Environment and Planning, Vol. 47, pp. 727-742.

Douglas, M. (1972), "Deciphering a meal”, Daedalus, Vol. 101 No 1, pp. 61-81. Reprinted in Implicit Meanings: Essays in Anthropology, Routledge, London (1975), pp. 249-275.

Epp, A.M. and Price, L.M. (2008), "Family identity: A framework of Identity Interplay in Consumption Practices”, Journal of Consumer Research, Vol. 35 Issue: June, pp. 50-70.

Epp, A., Jensen Schau, H. and Price L. (2014), "The Role of Brands and Mediating Technologies in Assembling Long-Distance Family Practices", Journal of Marketing, Vol. 78, pp. 81-101. 
Farrell, L.C., DiTunnarielo, N. and Pearson, J.C. (2014), "Exploring Relational Cultures: Rituals, Privacy Disclosure and Relational Satisfaction”, Communication Studies, Vol.65 Issue: 3, pp. 314-329.

Favell, A. (2008), "The New Face of East West Migration in Europe", Journal of Ethnic and Migration Studies, Vol 34 Issue: 5, pp. 701-716.

Fischer, E. and Otnes, C.C. (2006), "Breaking new ground: developing grounded theories in marketing and consumer behaviour", in Belk, R.W. (Ed), Handbook of Qualitative Research Methods in Marketing, Sage, London, pp.19-30

Gill, V. (1999), "Doing household research: interviewing couples together and apart", Area, Vol. 31 Issue: 1, pp. 67-74.

Glaser, B. and Strauss, A. (1967), The Discovery of Grounded Theory: Strategies for Qualitative Research, Aldine, Chicago.

Hertz, R. (1995), “Separate but Simultaneous Interviewing of Husbands and Wives: Making Sense of Their Stories”, Qualitative Inquiry, Vol. 1 Issue: 4, pp. 429-451. Hill, R., P. and Somin, L. (1996), "Immigrant Consumers and Community Bonds: Fantasies, Realities and the Transition of Self-Identity", Advances in Consumer Research, Vol. 23, pp. 206-208.

Hobsbawm, E. (1983), The Invention of Tradition, Cambridge University Press, Cambridge.

Huff, A.D., and Cotte, J. (2016), "The evolving family assemblage: how senior families “do" family", European Journal of Marketing, Vol.50 Issue5/6, pp. 892915.

Kalmijn, M. (1998), “Inter-marriage and homogamy: causes, patterns, trends”, Annual Review of Sociology, Vol. 24, pp. 395-421. 
Karanika, K., and Hogg, M.K. (2016), "Consumption through the ambivalent prism of intergenerational support”, European Journal of Marketing, Vol. 50 Issue3/4, $575-601$

Kemmer, D., Anderson, A. S., and Marshall, D. W. (1998), "Living together and eating together: changes in food choice and eating habits during the transition from single to married/cohabiting", The Sociological Review, 46(1), 48-72.

Kerrane, B., Bettany, S.M. and Kerrane, K., (2015), "Siblings as socialization agents: Exploring the role of 'sibship' in the consumer socialization of children". European Journal of Marketing, Vol.49 Issue: 5/6, pp. 713-735.

Kerrane, B., Bettany, S.M. and Hogg, M.K. (2014), "Revisiting contemporary issues in family consumption”, Journal of Marketing Management, Vol. 30 Issue: 1516 , pp. $1527-1532$.

Kipnis, E., Broderick, A. and Demangeot, C. (2014), “Consumer Multiculturation: Consequences of multi-cultural identification for brand knowledge," Consumption, Markets and Culture, Vol.17 Issue: 3, pp. 231-253.

Lindridge, A. M., Peñaloza, L. and Worlu, O. (2016), “Agency and empowerment in consumption in relation to a patriarchal bargain: The case of Nigerian immigrant women in the UK”, European Journal of Marketing, Vol.50 Issue: 9/10, pp.16521671.

Lindridge, A. M., Hogg, M.K. and Shah, M. (2004), "Imagined Multiple Worlds: How South Asian Women in Britain use Family and Friends to navigate between "Border Crossings" between households and societal contexts", Consumption, Markets and Culture, Vol. 7 Issue: 3, pp. 211-238. 
Luedicke, M.K. (2015), “Indigenes' Responses to Immigrants' Consumer Acculturation: A Relational Configuration Analysis", Journal of Consumer Research, Vol.42 Issue: 1, pp. 109-129.

Luedicke, M.K. (2011), “Consumer Acculturation Theory: (Crossing) Conceptual Boundaries", Consumption, Markets and Culture, Vol. 14 Issue: 3, pp. 223-244.

McCorkindale, L.M. (1992), "What is taste?", Nutrition and Food Science, Vol. 6 Issue: Nov/Dec,pp. 163-176.

McCracken, G.M. (1988), The Long Interview, Sage, Newbury Park, CA.

McFadden, L and Moore, G.L. (2001), "Intercultural Marriage and Intimacy; Beyond the Continental Divide", International Journal for the Advancement of Counselling, Vol. 23, pp. 261-268.

Miller, D. (1998), A Theory of Shopping, Cornell University Press, Ithaca.

Molina, B., Estrada, D. and Burnett, J.A. (2004), "Cultural Communities: Challenges and Opportunities in the Creation of "Happy Ever After" stories of intercultural couple hood", The Family Journal: Counselling and Therapy for Couples and Families, Vol. 12, pp. 139-147.

Montgomery, B. (1993), "Relationship Maintenance Versus Relationship Change: A Dialectical Dilemma”, Journal of Social and Personal Relationships, pp. 205-224. Newholm, T. and Hopkinson, G.C. (2009), "I just tend to wear what I like: contemporary consumption and the paradoxical construction of individuality", Marketing Theory, Vol. 9 Issue: 4, pp. 439-462.

Palan, K. M. and Wilkes, R.E. (1997), "Adolescent-parent interaction in family decision making”, Journal of Consumer Research, Vol. 24 Issue: 2, pp. 159-170. 
Pearson, J.C., Child, J.T. and Carmon, A. (2011), "Rituals in Dating Relationships: The Development and Validation of a Measure", Communication Quarterly, Vol. 59 Issue: 3, pp. 359-379.

Peñaloza, L. (1989), “Immigrant Consumer Acculturation”, Advances in Consumer Research, Vol.16, pp. 110-116.

Peñaloza, L. (1994), “Altravesendo Fronteras/Border Crossings: A Critical Ethnographic Exploration of Mexican Immigrants", Journal of Consumer Research, 21 (June), 32-54.

Putnam, T. (1999), "Postmodern Home Life", in I. Cierad (ed.) At Home: An Anthology of Domestic Space, Syracuse University Press, Syracuse, pp.144-152

Qian, Z. and Lichter, D.T. (2007), "Social boundaries and marital assimilation: Interpreting trends in racial and ethnic intermarriage", American Sociological Review, Vol. 72 Issue: 1, pp. 68-94.

Rawlins, W.K. (1983), "Negotiating Close Friendships: The Dialectic of Conjunctive Freedoms", Human Communications Research, Vol. 9, pp. 255-266.

Rook, D.W. (1985), “The Ritual Dimension of Consumer Behaviour”, Journal of Consumer Research, Vol.12 Issue: 3, pp. 251-264.

Sabourin, T. (2003), The Contemporary American Family: A Dialectical Perspective on Communication and Relationships, Sage, Thousand Oaks, CA.

Sandıkc1, Ö., and Ger, G. (2010), "Veiling in style: How does a stigmatised practice become fashionable?", Journal of Consumer Research, Vol. 37 Issue: June, pp. $15-36$.

Silva, L.C., Campbell, K. and Wright, D.W. (2012), "Intercultural Relationships: Entry, Adjustment and Cultural Negotiations", Journal of Comparative Family Studies, Vol. 59, pp 857-870. 
Smith-Maguire, J. and Matthews, J. (2014), "Introduction: Thinking with Cultural Intermediaries", in Smith-Maguire, J. and J. Matthews The Cultural Intermediaries Reader (Eds.), Sage, Thousand Oaks, CA.

Thompson, C. J., Locander, W.B. and Pollio, H.R. (1989), "Putting Consumer Experience Back into Consumer Research: The Philosophy and Method of Existential-phenomenology”, Journal of Consumer Research, Vol. 16 Issue: 2, pp. $133-46$.

Turner, V. W. (1972), "Passages, margins and poverty: religious symbols of communitas”, Parts I and II, Worship, Vol.46, pp. 390-412, pp. 482-494.

United Nations (2017), Statistical Yearbook, International Migrants and Refugees, Issue 60, p.51, https://unstats.un.org/unsd/publications/statistical-yearbook/

Weinreich, P. (2009), “'Enculturation', not 'acculturation': Conceptualising and assessing identity processes in migrant communities", International Journal of Intercultural Relations, Vol. 33, pp. 124-139.

Wong, P., Hogg, M.K. and Vanharanta, M. (2016), “Couples' narratives of shared self, possessions and consumption experiences", Journal of Consumer Behaviour, Vol. 16 Issue: 1, pp. $72-81$.

Wood, J. T. (1982), “Communication and relational culture: Bases for the study of human Relationships", Communication Quarterly, Vol. 30, pp. 75-84.

Yaprak, A. (2008), "Culture study in international marketing: A critical review and suggestions for future research”, International Marketing Review, Vol. 25 Issue: 2, pp. $215-229$.

Yerby, J., Buerkel-Rothfuss, N. and Bochner, A.P. (1998), Understanding Family Communication, $2^{\text {nd }}$ edition, Allyn and Bacon, Needham Heights, MA. 